\title{
Reflections on integrated research from community engagement in peatland restoration
}

\author{
A. Fleming $\mathbb{1}^{1 凶}$, S. Agrawal ${ }^{2}$, Dinomika², Y. Fransisca ${ }^{3}$, L. Graham ${ }^{4,5}$, S. Lestari ${ }^{6}$, D. Mendham¹, D. O'Connell ${ }^{1}$, \\ B. Paul ${ }^{2}$, M. Po ${ }^{1}$, A. Rawluk ${ }^{7}$, N. Sakuntaladewi ${ }^{8}$, B. Winarno ${ }^{6}{ }^{6} \&$ T. W. Yuwati ${ }^{6,9}$
}

Community engagement and integrated research are key approaches to solving complex socio-ecological challenges. This paper describes the experience of bringing together a team of natural and social scientists from Australia and Indonesia in the 'Gambut Kita' (translated as 'Our Peat') project. Gambut Kita aims to produce new knowledge and support efforts to successfully, and equitably, restore Indonesia's tropical peatlands and ensure that livelihoods can be maintained on restored (rewetted) landscapes. The paper focuses on experiences of using community engagement for integrated research. It discusses three community engagement approaches used in the project-resilience, adaptation pathways and transformation approach (RAPTA), participatory rural appraisal (PRA), and community-led analysis and planning (CLAP). It also describes the qualitative analysis of 14 interviews with the project team of lessons learned in community engagement for integrated research. 'Criteria for success' from the literature on international development projects is used to assess progress. The findings highlight the specific complexities of working across countries and cultures. Successful community engagement is not so much about the 'tool' but about the trust, agency, and support to change. The tools do, however, have different strengths. PRA and CLAP can build deep community understanding and relationships. RAPTA has strengths in framing visions and pathways to the future, systems thinking, anticipatory learning, and taking a cross-scale systems view which is required to solve many of the problems manifesting at local or community scales. Similarly, success in integrated research is not just about individuals, but structures (e.g. explicit process) and infrastructure (e.g. access to technology). These findings suggest that integrated research needs special considerations in terms of design, and these relate across scales to individual researchers as well as teams, leaders and organisations. Integrated research projects need careful, inclusive, iterative management with a lot of interaction to learn from each other, build a common vision, achieve clarity of roles, and share emerging findings.

\footnotetext{
${ }^{1}$ CSIRO Land and Water, Hobart and Canberra, Australia. ${ }^{2}$ Yayasan Tambuhak Sinta (YTS), Palangkaraya, Indonesia. ${ }^{3}$ RMIT University,

Melbourne, Australia. ${ }^{4}$ Borneo Orangutan Survival Foundation, Bogor, Indonesia. ${ }^{5}$ University of Sunshine Coast, Brisbane, Australia. ${ }^{6}$ Forest Research and Development Center, Ministry of Environment and Forestry, Bogor, Indonesia. ${ }^{7}$ University of Melbourne, Melbourne, Australia. ${ }^{8}$ Center for Research and Development on Social Economy Policy and Climate Change, Jakarta, Indonesia. ${ }^{9}$ Banjarbaru Environment and Forestry Research and Development Institute, Banjarbaru, South Kalimantan, Indonesia. $\bigotimes_{\text {email: Aysha.Fleming@csiro.au }}$
} 


\section{Introduction}

avigating complex social-ecological challenges with pressing on-ground impacts to communities, such as the restoration of tropical peat swamp forests (herein, peatlands) in Indonesia, requires the integration of diverse knowledges and perspectives (Rawluk et al., 2020). Knowledge integration and critical reflection-such as that fostered by interdisciplinary research-have great potential for addressing issues of social ecological justice (Collard et al., 2018). Interdisciplinary research with community engagement-dynamic interactions and communication between a community and an external party - can develop creative, transformative futures that challenge and grapple with historical and cultural assumptions (Hernandez et al., 2020) and produce careful and deliberate practice to reflect the diversity of, and appropriately capture the views and perspectives of, those it aims to support (Bammer, 2013). However, little attention has been given to the choice and design of community engagement practices for integrated research. In this paper, we reflect on three community engagement methods used for transdisciplinary research and their strengths, challenges and opportunities.

The problem context for this paper is the social ecological challenge of peatland restoration in Indonesia. Miettinen et al. (2016) reported that only $6 \%$ of peatlands remain untouched, while much of the remaining area has been cleared and drained for agriculture and plantations since the 1980s. Oxidation of these peatlands is a significant source of $\mathrm{CO}_{2}$ (emitting around $120 \mathrm{Mt}$ $\mathrm{C} / \mathrm{y}$ from Indonesia), while the fire in drained peatlands emits a similar quantity of $\mathrm{CO}_{2}$ (Miettinen et al., 2017), both combined represent around $60 \%$ of Indonesia's national $\mathrm{CO}_{2}$ emissions (UNFCCC, 2016). Burning peatland is also the source of much of the smoke haze that is an annual economic and human health disaster across many parts of SE Asia.

Cleared and drained peatland is a significant fire risk because peat fires that burn underground can be very challenging to extinguish (Goldstein et al., 2020). Restoring these peatlands has become a national priority for Indonesia, and an international priority for the region. Peatlands in Indonesia are critical habitats for endangered animals (IUCN, 2019), as well as having become vital sources of livelihood for millions of people. Restoration requires transformational change in how these communities undertake their livelihoods. The need for community engagement is paramount because of the complexities associated with these peatland restoration programmes (Dohong et al., 2017, 2018; Medrilzam et al., 2017; Purnomo et al., 2017; Sanders et al., 2017, 2019, 2020).

Once the degradation process starts, tropical peatlands often descend into a cycle of retrogressive succession, as has occurred in the area of the Mega Rice Project. Established by the Government of the time in 1996-1999, the Mega Rice Project created tens of thousands of canals across 1.2 Mha of Central Kalimantan's tropical peatlands, with the worthy aim of allowing Indonesia to achieve self-sufficiency in terms of rice production (Medrilzam et al., 2017). Due to technical problems, the project was unsuccessful, resulting in thousands of displaced transmigrants, and fires on a massive scale (Medrilzam et al., 2017; Muhamad and Rieley, 2001). Subsequent governments have prioritised restoration of this landscape however, challenges remain because of ongoing issues with land tenure, decentralisation and the vast ecological alterations (Medrilzam et al., 2017). Subsequently, the Indonesian Government, along with national and international NGO partners and scientists have been trying to restore these drained, burned, and degraded tropical peatlands for over 20 years, but with only limited success. Restoration efforts have largely failed because of the complexities involved in the landscape and the range of stakeholders with conflicting needs and objectives.

Through establishing the Badan Restorasi Gambut (BRG, or Peatland Restoration Agency) in 2016, the Indonesian government committed to rewetting, revegetating and revitalising $2 \mathrm{Mha}$ of degraded peatland (Giesen, 2018). The aim of the restoration was primarily intended to reduce peat fires, which cause severe smoke haze and damage international relations and the national economy, are a significant source of greenhouse gas emissions and a health concern (Marlier et al., 2015; Hu et al., 2018). The BRG was established in response to the 2015 fires, which along with the 1997 fires, are considered the worst ever experienced in Indonesia. The BRG is already restoring some peatlands of Indonesia (e.g. in Pulang Pisau, Central Kalimantan) through blocking (damming) the channels that had been previously installed to drain the peat for agricultural crops and plantations. Rewetting is not a straightforward process, with many technical and social issues arising. There are still many knowledge gaps in the rewetting process itself: whether the dams work as intended; whether the peat will stay fully wet and recover their original soil properties; and what alternative livelihood options are available to communities. Furthermore, different communities have different levels of awareness and understanding of rewetting, and variably support or oppose rewetting and changing livelihoods. Transformation is required at multiple levels-in terms of a new rewetted ecosystem, new livelihoods and new policies to prevent maladaptation (such as illegal logging). The Gambut Kita research project was established to better understand how to support this transition equitably and sustainably to restored peatlands that meet the needs of local communities.

The issue of rewetting and restoring peatlands presents a complex challenge because it has social, political, economic, environmental and technical aspects (see Fig. 1). To address this complexity and derive solutions that will lead to equitable and sustainable peatland restoration, there is a need to employ integrated research-which we see as an umbrella term for interdisciplinary and transdisciplinary research, integrating academic researchers from different disciplines (interdisciplinary research), as well as non-academic participants, in pursuing a common goal, and creating new knowledge and theory (transdisciplinary research) (see Table 1). Gambut Kita includes stakeholders on the ground, in this case, villagers and other government and nongovernment organisations in Indonesia.

Integrated and interdisciplinary research has its own scholarship (Pooley et al., 2014) but it can be difficult for researchers to access this knowledge because it is 'fragmented' (Bammer, 2013) and it is a task to keep up with the increasing literature of even one discipline. Opportunities to learn, reflect and improve are essential to building the capacity of individuals and teams but are also relevant at organisational levels. Interdisciplinary research training, both formal and informal, can be valuable (Lyall and Meagher, 2012), and is needed across levels and disciplines (Alexander et al., 2019) but it is also acknowledged that making mistakes is inevitable and requires a 'constructive sharing of experience' (Cornell et al., 2013, p. 69). Embracing this from the outset is important in both individual and organisational conceptualisations of success (Bammer, 2013; Roux et al., 2017; Cundill et al., 2019).

Such a complex research initiative as the Gambut Kita project requires careful and sensitive community engagement by experienced organisations to work with local communities to facilitate change. It is vital that the villagers are actively involved in the process of identifying options for livelihoods on rewet peat so that those options are relevant, realistic and appropriate 


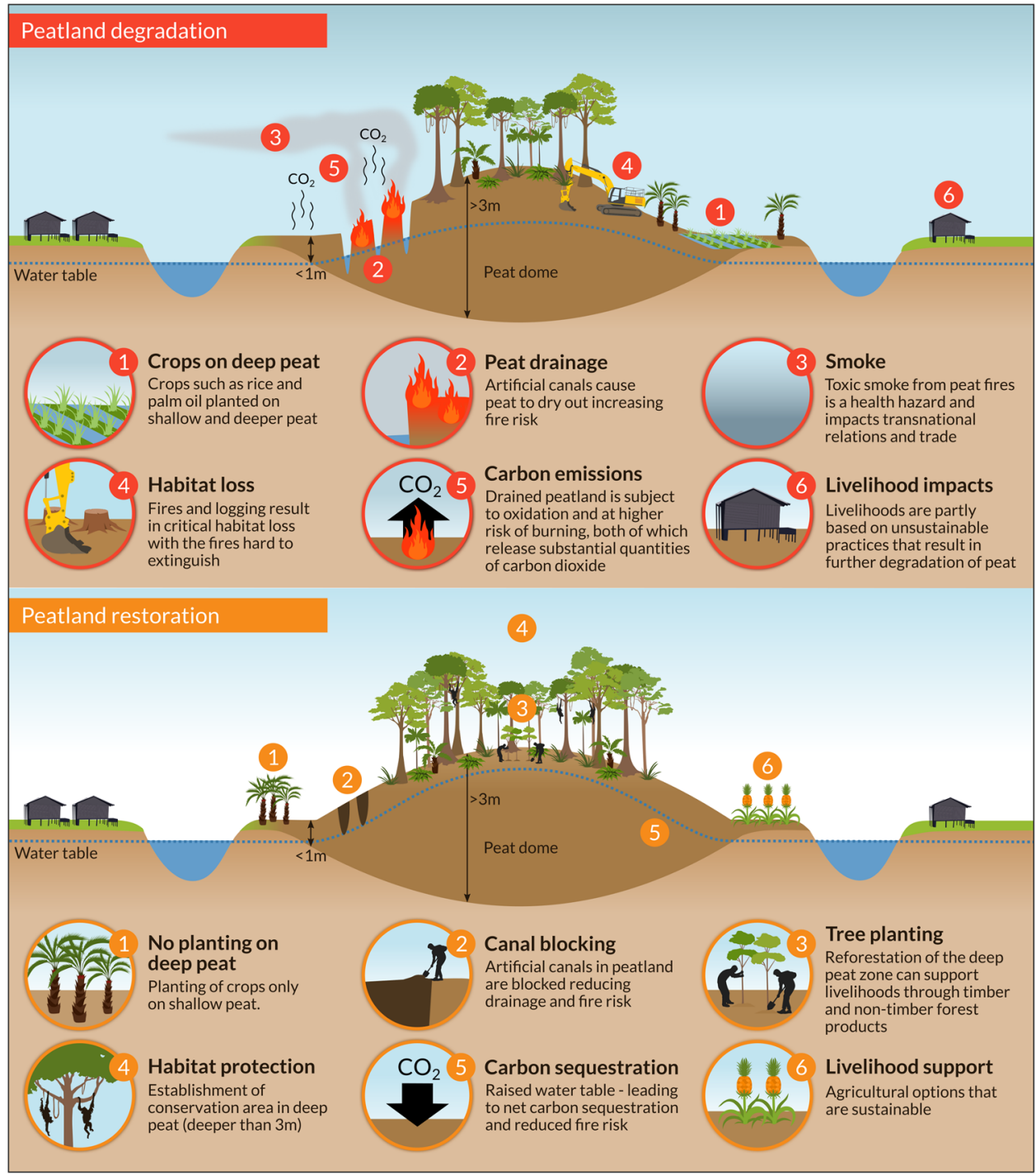

Fig. 1 A comparison of peatland degradation and peatland restoration. The figure shows the complexity involved across crops, burning, habitat loss, carbon emissions and livelihood impacts.

\section{Table 1 Note on terminology utilised in the paper.}

Multidisciplinary projects involve different academic disciplines researching a single problem or theme but working in parallel without integration. Interdisciplinary projects involve unrelated academic disciplines in a way that requires them to cross disciplinary boundaries to create new knowledge and theory in pursuit of a common research goal.

Transdisciplinary projects integrate academic researchers from unrelated disciplines, and nonacademic participants, in pursuing a common goal, and creating new knowledge and theory.

Source: Tress et al. (2006).

Gambut Kita fits the definition of a transdisciplinary project, yet many of the participants were more comfortable speaking about interdisciplinarity, because the project is still a work in progress, transformation has not yet been achieved, and because the processes of working together are still difficult and evolving. We use the term integrated research throughout as a descriptor for both (Tress et al., 2004).

(Sanders et al., 2020). In this project, three different approaches were trialed in different regions of Indonesia at different stages of restoration. This paper describes the processes involved in each, explores the strengths as well as the limitations and integrates insights from all three to extend current understandings of supporting integrated research in general (Rawluk et al., 2020) and in the peatlands in particular (Sanders et al., 2020; Uda et al., 2019).

The Gambut Kita project was funded by the Australian Center for International Agricultural Research (ACIAR) for the period
2017-2022. The project has five objectives relating broadly to fire management, livelihoods on peat, dynamics of water and nutrients in peat soil, policy implications, and knowledge management. All of the interviews conducted for this paper were from the livelihoods objective which has the aims to (1) generate new knowledge to support efforts to successfully and equitably restore peatlands and (2) ensure that livelihoods can be maintained on restored (rewet) peatlands. This paper focuses on our experience of integrated research and lessons learned from the methods we 


$\begin{aligned} & \text { Table } 2 \text { Summary of disciplines in Australian and Indonesian } \\
& \text { team members (and interviewees). }\end{aligned}$
\begin{tabular}{lll} 
Discipline & Australia & Indonesia \\
\hline Natural science & $\begin{array}{l}\text { 1 senior researcher } \\
\text { (project leader) }\end{array}$ & 1 senior researcher \\
& 1 junior researcher & \\
Social science & 3 senior researchers & 2 senior researchers \\
Non-academic, & 1 junior researcher & 1 junior researcher \\
e.g. NGO & 0 & 4 practitioners \\
\end{tabular}

employed, to extend current understandings of transformative research implementation. The findings from the broader research, such as livelihood options on rewet peat, are not discussed here.

The methods we employed in the field which we explore in more detail below are three approaches used to engage with the community:

- Resilience, adaptation pathways and transformation approach (RAPTA),

- Participatory rural appraisal (PRA) and

- Community-led analysis and planning (CLAP).

The next section of the paper describes the methods and outlines the different components of the approaches. The results present our experiences of the similarities and successes as well as the limitations and reflections from using these community engagement methods, according to our reflections and the literature on the topic. Finally, we integrate insights from all three methods to extend current understandings of supporting integrated research and reflect on our own experiences to provide lessons learned for integrating across disciplines and multiple knowledge sources (including local knowledge).

\section{Methods}

The Gambut Kita project began in 2017 and will run until at least 2022. Activities have included annual meetings with funders and stakeholders, held in Indonesia, and online meetings during 2020 and 2021 due to the coronavirus pandemic. Other activities included weekly online meetings for each team, annual writing workshops in Indonesia, a gender workshop in Australia, regular on-ground project activities in Indonesia with communities and stakeholders, stakeholder workshops in Indonesia in 2019 and a RAPTA training workshop in Indonesia in 2019. The project also conducted a comprehensive theory of change workshop online in 2020. Ethics approval was granted from CSIRO Social and Interdisciplinary Science Human Research Ethics Committee $122 / 18$.

Project team. The project team that was established to explore livelihoods on rewet peat was deliberately integrated and crosscultural, consisting of a range of research and development expertise in natural and social sciences in both Australia and Indonesia (Table 2). An NGO in Indonesia was included as part of the project team to work closely with the Indonesian communities. While each team member had experience with integrated work in other contexts, including in international work, the project team was new to working with each other and many were new to working in peatlands. In addition, the project construct and research design was initially largely multidisciplinary rather than inter- or transdisciplinary, stemming from the way that it was developed by different parties and operating across different objectives. The project team brought together knowledge about natural sciences (soil science, agroforestry, hydrology) and social science (social change processes and systems thinking) as well as local knowledge about communities, culture, traditions, and histories. Bringing these different pieces of knowledge together required substantial time spent getting to know each other and working to understand the project goals and objectives.

The team worked with communities in South Sumatra (Kayu Labu, in Ogan Komerang Ilir, or OKI district), and Central Kalimantan (Tumbang Nusa, in Pulang Pisau district). Kayu Labu is around $3 \mathrm{~h}$ drive from Palembang $(126 \mathrm{~km})$. The population of Kayu Labu is 2744 people, with 817 households, including migrants from Java and Lampung. The most common livelihood strategies are fishing and livestock, followed by palm oil, rubber and vegetable cultivation. The population in Tumbang Nusa village is 962 people, with a total of 286 households (BRG, 2018). The majority of the inhabitants of Tumbang Nusa village are fishermen, while some work as traders, in tree nurseries, or breed goats, cows or swallows.

\section{Community engagement methods}

Resilience, adaptation pathways and transformation assessment. RAPTA is a framework that combines existing methods and $\mathrm{t}$ ools together (https://research.csiro.au/eap/rapta/). The aim of RAPTA is to identify where and how to make a purposeful intervention in a system to respond to uncertain and rapid change and move towards sustainability (O'Connell et al., 2019). The components of RAPTA include scoping and goal setting, stakeholder mapping and engagement, imagining change, describing the system, exploring scenarios, analysing the system, generating options, sequencing pathways and implementing pathways (O’Connell et al., 2019).

RAPTA was used in a capacity-building workshop for the Indonesian members of the project team in September 2019 in Palembang and components learned during the workshop informed engagement with communities in South Sumatra in 2021. RAPTA has been used in other contexts to help communities grappling with complex change (O'Connell et al., 2019).

Participatory rural appraisal. PRA is an approach used in international development projects to incorporate the knowledge and opinions of local people in the planning and management of development projects and programmes. PRA is a set of approaches and methods that aim to empower communities by involving them in the process of identifying resources, strengths and analysing issues in their own context and then creating a plan to address these. PRA was first developed around 1990 with multiple NGOs in India and elsewhere experimenting with making the techniques of Rapid Rural Appraisal more participatory (Chambers, 1994). Techniques covered by PRA include understanding group dynamics, social mapping, interviewing and group discussion, history of the village, timelines of assistance, natural resource management, trend analysis, seasonal calendar, wealth ranking, economic analysis and analysis of gender roles. In-depth interviews are also often part of PRA methods and were used in Tumbang Nusa in 2019. Further PRA activities, including interviews and workshops, are planned for Kayu Labu in 2021. See also Narayanasamy (2009) and Castelloe and Gamble (2005) for other examples of PRA.

Community-led analysis and planning. CLAP is a variation of the PRA methodology (Shah, 1994) that was adapted specifically for conditions and communities in Central Kalimantan by Yayasan Tambuhak Sinta (YTS, an NGO), working in Indonesia (https:// www.sdbritain.org.uk/yayasan-tambuhak-sinta), and has been in use since 2004. CLAP and PRA share many of the same tools and techniques and both are designed to enable the community to 


\section{Table 3 Common characteristics and key differences for the three community engagement methods.}

Characteristics common to RAPTA, PRA and CLAP

- Uses inclusive techniques for all ages and skills

- Highlights aspirations and values

- Can adapt tools and techniques to the cultural context

- Aims to empower the community to enact change

- Supports interdisciplinary research (if explicitly planned)

- Language can be a limitation for external facilitators

- Requires extended time with the community

- Requires general village information prior to visit

- Requires approvals (e.g. from government and village head)

- Requires skilled and trained facilitators

- Requires active community participation

Key differences in approaches

- RAPTA emphasises system change and critical thinking while PRA and CLAP emphasise participant knowledge and experience

- RAPTA starts with a vision of the future while PRA and CLAP start with the historical and current context

- RAPTA explores governance arrangements as change pathways while PRA and CLAP explore governance as part of the current context

- RAPTA emphasises active and structured learning while PRA and CLAP emphasise local knowledge

- RAPTA designs change pathways so participants can independently implement change after the activity ends and revisit and adjust their pathways, while PRA and CLAP support change pathways with return visits and on-going relationships building trust

- PRA and CLAP follow clearly defined methods to build facilitator confidence while RAPTA is more open

Unique attributes

- RAPTA focuses on the whole system and highlights connections, cross-scale dynamics, impacts and key points of intervention. It requires facilitators with skills in systems thinking to develop an understanding of which change pathways participants have agency for, which pathways others drive,

barriers and feedback loops across scale

- RAPTA focuses on future states and transition pathways and approaches to deal with complexity and uncertainty and scales of change

- RAPTA requires explicit attention to ethics

- CLAP is usually run in the same way building rigour and expertise over time, but reducing ability for spontaneity

- CLAP embeds researchers in village life, staying with local families and building trust and lasting relationships

- CLAP is co-facilitated by (pre-trained) villagers creating strong ownership, the selection of these facilitators is important

- PRA has a long history and is widely employed; it has a strong reputation and is evolving over time

Common challenges

- RAPTA and PRA may risk shallow engagement if not enough time taken

- RAPTA and PRA may raise discomfit in exploring socio-political dynamics

- PRA and CLAP may need to validate some subjective data collection

create a community development plan, based on the analysis they do during the engagement process. The CLAP analysis covers key aspects of community life-the economy, the environment, social conditions, resource use, livelihoods and local institutions. With this plan, they can more readily access support from the government, Civil Society Organisations and the private sector. The CLAP is used by YTS to initiate a long-term relationship with the village-the 7 days of intensive engagement with the community creates a strong bond and sense of trust, and the results of the community's analysis provide a comprehensive platform for future engagement and support. It was chosen for the project to enable deep engagement with the community and a comprehensive understanding of community realities and dynamics. Crucially, selected villagers are engaged from the beginning to act as facilitators and co-lead the activities. A CLAP process was conducted in Tumbang Nusa village, Pulang Pisau district, Central Kalimantan Province on 14-17 March 2019. Since then, YTS has had ongoing engagements with the village to develop and implement training programmes for a new rubber enterprise and work on supporting new market opportunities. This demonstrates that the CLAP has resulted in positive change in the community. Other examples of CLAP in practice can be found at Yayasan Tambuhak Sinta|Susila Dharma Britain (sdbritain.org.uk).

Interviews with the project team. To ascertain the different strengths and limitations of these three approaches in terms of successful community engagement and change and ability to support interdisciplinary research, 14 structured interviews were conducted with all of the project team (see Table 2) in 2020. The interviews focused on the RAPTA/PRA/CLAP methods, but also discussed participatory and integrated research to capture the reflections and experiences of the team (see Table S1 Supplementary Information for the full list of questions). The interviews were transcribed and analysed using NVIVO 12 qualitative data analysis software. Codes were constructed from the data following methods of inductive grounded theory (Fleming et al., 2019) and organised into themes around participants reflections on the strengths and limitations of community engagement approaches and the strengths and limitations of integrated research.

The results of the interviews are captured in Table 3 comparing the three approaches. This is followed by a discussion of the key learnings relevant to other contexts and reflections on the success of integrated and international development research linked with relevant literature.

\section{Results}

The reflective interviews demonstrated that each community engagement approach was seen to have some key characteristics, some of which were shared and some of which were unique. These are summarised below.

The interviews revealed that many of the underlying tools used in each community engagement approach have the same intent. For example, the focus on participatory methods, mapping and visualisation, storytelling and elicitation of values, aspirations and capacity development. Many of the interviewees saw CLAP and PRA as the same approach, differentiated only by the manner of delivery and level of structure. CLAP is delivered by organisers who stay in the village and train local co-leads to help facilitate, and its structure tends to follow a similar sequence. RAPTA was 
not considered to have been fully employed in the community and so many interviewees felt unable to comment on all aspects of this approach in practice.

Despite the strong connection between the three approaches, each was seen to have unique strengths and limitations. For PRA and CLAP, the main strength was the level of contextual detail of the data and the authenticity of the data.

"[CLAP is for] enabling and providing an environment in which local people reveal what they know. They share their knowledge, their experience of the environment which they are living and working in so there is this rich outflowing of knowledge, information and experience that is so important to inform what we want to do. We need to really, deeply understand the context, not just the physical context but the social, cultural and the human, the human domain is very complicated." Int 3.

"PRA is like a bridge to network with the local community and we have more variation of information, not only from the perspective of the social condition but their livelihood, history and politics." Int 2.

For RAPTA the future focus and ability to empower villagers to navigate uncertainty and transition was the main strength, although this was limited with the target community due to a lack of facilitator confidence and a lack of time. However, RAPTA was usefully employed in the project in capacity-building workshops for the team, which developed skills in system thinking, analysis of change processes and anticipatory learning.

"RAPTA is, you can implement it to look at where the community wants to be and the tool, meaning like the policy or any structural change, institutional change that needs to occur to take them from A to B, RAPTA can map all of that out." (Int 5).

"CLAP and PRA are good for understanding the current situation. RAPTA is good for understanding how to transition, how best to manage that social transition to a new state." (Int 7).

"with RAPTA we could understand what they want to be with the peatland and also what they think and what they have been doing so far with the peatland and in what way we can move together towards the thing they want to have with the peatland." (Int 1).

RAPTA was also considered as the method most able to support interdisciplinary research. CLAP and PRA were seen to be able to support interdisciplinary research through the provision of useful data of interest to different disciplines and through involving different disciplines working together if intentionally designed to do so.

"RAPTA may have more potential for working in an interdisciplinary way but we've struggled to implement that on the ground and hopefully we can but it's been slow progress so far." (Int 7).

Time required in the village and skills in facilitation were considered limitations for all three approaches. Limitations of PRA and CLAP were that in starting from the current context, it can limit the ability to think creatively about more dynamic and uncertain futures. While the CLAP tool can be used to develop future village plans, starting from the point of view of what has already happened tends to frame possibilities for change more within the status quo than transformation. For RAPTA the frequent changes in political context and the complexity of networks of power and influence were a barrier to developing effective pathways for change. Ownership over the plans developed in the village was another aspect highlighted for RAPTA and CLAP, which particularly focus on facilitating a pathway to change. If the village participants are not committed to the activities continuing after the process and are engaging for other reasons (e.g. some participants are paid, some do it as duty, some do it for novelty), the work will cease when the engagement ends and the change pathway will not be successful.

The opportunities for PRA and CLAP are that they provide a good basis for building relationships and understanding of the community context, which is an excellent foundation of knowledge. Rather than being stand-alone, PRA and CLAP provide the opportunity for ongoing work and collaboration in the village and work best as part of longer-term programmes.

"In PRA we are trying to understand the situation of the local community from many perspectives-social, cultures, politics, biophysics, but it is only the beginning and you have to complement this with the other tools." (Int 2).

"[CLAP] is really a wonderful tool to elicit people to open up and over the period of four days, or six actually, people come to bond with the project and the people in the project, eating together, sleeping together and they become more and more open and they respect and trust who we are and what we are trying to do and that provides a wonderful foundation to start a project to start an activity, because you have a deep understanding of the context and you have these relationships already where people are happy to see you and they want to help and they feel that you are going to help them somehow." (Int 3).

The opportunity for RAPTA is it too would benefit from longer-term check-ins and adjustments set up to enable the participants to be able to make their own changes without the expert facilitators, if there is sufficient ownership and commitment from the villagers to take the pathways forward. However, changes in the broader context, such as political shifts in power and decisions may make this process hard for villagers to accomplish, if they lack the visibility of (or ability to influence) where and how decisions that affect them are made.

"PRA is not able to take us through the change dimensions in the way we want to take the community and so that is where RAPTA comes in to understand what change is needed to occur and where we want to end up." (Int 5).

Reflections on conducting participatory and integrated research. As well as reflecting on the methods employed with communities, the interviews discussed the challenges and opportunities of integrated research. Every interviewee considered trans- and interdisciplinary research to be essential in providing 'comprehensive solutions' from 'multiple perspectives' for addressing complex, interconnected and messy problems like sustainable livelihoods on rewetted peatland. Every interviewee also thought that more diverse, participatory research would only increase in the future of applied research. The key factors for success in integrated research are perceived to be an open mind and a willingness to try new things, to have respect for others and to commit to something greater, accepting some level of discomfort or confusion, to achieve a bigger vision for change.

"I think it starts from ourselves, if we want this project to succeed, we have to open our mind and our understanding to start to understand others and evaluate what is the core purpose of the project." (Int 2). 
However, every interviewee also noted that integrated research was difficult and had many barriers. Successfully integrating across disciplines for an on-ground outcome was not seen to be guaranteed, but still worth trying for. A lot of value was placed on the willingness to persevere and the gradual process of building relationships, awareness and respect for others and building capacity to be resilient, suspend your own beliefs about how things should be and learn to work differently. The interviewees noted that working in interdisciplinary teams is always hard, but for the Gambut Kita project, working far apart in two countries with different cultures was the biggest issue. The disciplinary divides between natural and social scientists were a minor issue compared to the logistic barriers preventing sufficient face-to-face communication, opportunities to get to know each other, and work 'shoulder to shoulder' and overcome the language barriers (both in terms of disciplinary terminology and English/Bahasa).

"I think you need everyone to be willing to come to the table and see everyone's perspective. The types of structural barriers, to communicate well, the personality differences, to listen to one another and the opportunity to interact and communicate effectively, talking to people in languages that we all understand." (Int 5).

In addition, the lack of 'being there' was a significant barrier for the Australian researchers not in Indonesia and for the Indonesian researchers not familiar with peatlands. The experiential knowledge of how things are, how things work and building connections with people over the long term cannot be captured remotely. This ranged from 'truly appreciating' the characteristics of peatlands, to understanding the livelihoods of people and the way that organisations and processes of decisionmaking work.

Opportunities to overcome the hurdles of interdisciplinary research were seen to be in strong leadership that enabled frequent and productive discussion, required regular participation, committed to a clear (but adaptable) plan and helped each member see their place in that plan. Other actions that individuals could take to improve the success of interdisciplinary research were seen to be in preparation (learning as much as possible about the content beforehand to understand the basic issues), being flexible in terms of personal expectations and frequent communication identifying assumptions, needs and current progress. Sharing information more, rather than less, was seen to be the best way to make sure people felt included, enabled and knowledge was integrated.

"In my opinion it requires openness from each individual and team members to listen to others particularly to understand what they say, not listen to reply, just admit that people also have their own expertise and experience and we've got to think and consider in talking through issues. Also it requires a willingness for commitment I think from the related parties to run or implement the collective solution.” (Int 4).

Processes that helped the team to build relationships and understanding were time spent face-to-face in capacity building workshops, especially those that used visioning exercises and processes of planning for change to help demonstrate shared values and aspirations and negotiate differences.

"I think it's helpful to have common values and principles that you are working from so when you do collaborate and work together it's much easier, you don't have to start from scratch with this is where I'm coming from and why etc. I think that's fundamental." (Int 3).
Efforts to develop a shared vision of the problem framing, the research questions, and what is trying to be achieved were noted as foundations to success.

"that idea right from the beginning of what does success look like? It is a bit of a cliché but it's actually a really important question in interdisciplinary research." (Int 8).

An important process that helped the team build understanding was weekly phone meetings to share information, however small, to keep people up-to-date and connected.

"The weekly meeting [has worked well] because we can talk about what everyone is doing. It provides an opportunity for us to link in and also form a group identity amongst us. The weekly meeting also irons out any potential issues that we can have." (Int 5).

The main difficulties described by the interviewees were about the geographic separation of the team, especially during COVID19 travel restrictions. Working across cultures also added difficulty about expectations, timeframes and communication and caused perceptions of a lack of integration.

"I don't know what people are doing, everyone is doing their own thing." (Int 6).

"If I were to do it better, I think I would have really clearly spelled out where the Australian and Indonesian team's roles and responsibilities are so I have a clear understanding of where I need to be. That's where I think the hardest part is. I don't really know where I fit in the whole scheme of things and I feel like I have to carve out where I'm needed." (Int 5).

In addition, there was the difficulty of keeping up with a constantly changing context, including political changes and local governance changes, changing objectives of leadership in partner organisations, environmental changes (fires and COVID-19), and changes in other groups and projects working on peatlands.

"In [location] we were delayed first by the election because we weren't quite sure who was going to be head of the district ... then once he was selected you kind of have to wait until they are settled and then go and find a location and then go and ask the different permissions and that is the formal leader and then you have to look out for the community leader and the informal leader, so all of that process, it is very tedious but necessary... we have to work with local government before they can go into the community because they have their process they needed to follow. That becomes convoluted and they don't have another way of doing it." (Int 5).

Interdisciplinary research was described by one participant as both a specific skill set and a dedicated task, which required resourcing and explicit attention, rather than as being assumed as part of individual's (or the project leader's) role.

"People don't seem to realise that working in an interdisciplinary or transdisciplinary way is an expertise in itself, skill and expertise. It's not as simple just as throwing a whole lot of people into a room and hoping for the best. And as well as a skill and an expertise it's actually a task and it needs to be resourced accordingly and it's usually not. It's usually expected to be an emergent property of putting a whole lot of disciplinary people in a room together." (Int 14). 
Table 4 Components of successful integrated research at different scales from the individual to the organisational scale were important to our project.

\begin{tabular}{|c|c|c|}
\hline $\begin{array}{l}\text { Individual (knowledge and } \\
\text { attitude) }\end{array}$ & $\begin{array}{l}\text { Team (attitude and } \\
\text { practices) }\end{array}$ & Project leadership (attitude and practices \\
\hline $\begin{array}{l}\text { - Attitude of respect and an } \\
\text { open mind } \\
\text { - Flexible expectations, } \\
\text { persistence and courage } \\
\text { - Commitment to continually } \\
\text { learn and to be kind to others }\end{array}$ & $\begin{array}{l}\text { - Explicit, inclusive } \\
\text { relationship building } \\
\text { - Time spent face to face } \\
\text { - Participation in frequent, } \\
\text { regular communication }\end{array}$ & $\begin{array}{l}\text { - Commitment to a collective vision and } \\
\text { clear communication of how unique parts } \\
\text { contribute to a greater whole } \\
\text { - Awareness and allowance for extra time } \\
\text { taken } \\
\text { - Adaptive learning and empathy in } \\
\text { relationships and communication }\end{array}$ \\
\hline
\end{tabular}

Individual (knowledge and attitude)

open mind

- Commitment to continually relationships and communication

\section{Organisational (practices)}

- Allow for longer time frames for projects

- Create collaborative instead of competitive structures (e.g. funding arrangements; rewards)

- Monitoring and evaluation which supports adaptive learning

\section{Table 5 Criterion for success in international development research projects with a focus on achieving integrated research.}

\section{Criterion for success (from Bartlett, 2018)}

How well was the project designed in terms of specific activities to address objectives and to facilitate adoption?

What has been achieved in terms of completed activities and specified outputs?

How well did the project team collaborate in conducting the research, and what new skills did the scientists gain?

What is the relative magnitude and quality of publications produced?

What is occurring as a result of the enhanced capacity?

How has the body of scientific knowledge been enhanced, and how is this knowledge being used?

Has the research led to improved livelihoods or facilitate economic development?

What changes to the social circumstances of project beneficiaries or the No change enabling policy environment have occurred that the project has contributed towards?

\section{Integrated research considerations}

Does the project have specific activities, processes and responsibilities to cross-cut objectives and synthesise findings?

Are completed activities and outcomes interdisciplinary and how is this recognised?

How well did the project team collaborate in integrating their research perspectives and what new interdisciplinary skills did the team members gain?

Is there a dedicated interdisciplinary output? How interdisciplinary are the publications produced?

What is occurring as a result of the enhanced capacity for interdisciplinary research?

How has the body of interdisciplinary scientific knowledge been enhanced and how is this knowledge being used?

No change

\author{
No change
}

Assessment of project. According to Dick et al. (2016), the 'why' of interdisciplinary research is unexplored in the literature but the 'how' has established literature and frameworks. Yet this strongly contrasts with our own experience. For us, the 'why' was self-evident given the complexity of the problem. It was the 'how' which was difficult because it required contextdependent skills and knowledge (including building networks, trust, and relationships). Generic steps to follow (e.g. Pooley et al., 2014) still had to be 'rediscovered' to work for us, in practice. We found that strong project leadership is essential to role model empathy, commitment and clarity of purpose and set out processes to explicitly integrate knowledge and to enable others to contribute to the whole as well as the part. Therefore, leadership training and tools for effective leadership can also be relevant to improve interdisciplinary research (Bammer, 2013). Leadership training should include transparency of decision-making, frequent and open consultation and discussion, problem framing and theory of change exercises, reflective and adaptive learning, and the logistics and infrastructure of communication (including access to technology) (O’Connell et al., 2019).

As team members and community facilitators grappling with complexity and multiple pieces of knowledge and perspectives, our work confirmed 'being open-minded' to be important in our project (Kelly et al., 2019), but we also identified the need for a change in knowledge, attitude and practices to go beyond the individual and team scale, in terms of leadership and organisational support (Roux et al., 2017; Cundill et al., 2019). While knowledge, attitude and practices are relevant across all scales of individuals, teams, leadership and organisations, each scale does tend to have a different focus (see Table 4). We highlight the relevant considerations from our project across scales below.

The importance of the need for factors that support interdisciplinary research to scale out from individual to team to leadership and to the organisation demonstrates that individuals cannot achieve successful, large-scale integrated research working only as individuals. It requires a common commitment to the value of integrated research from individual to organisational scales, with processes and settings designed to build trust and understanding. Sharing and challenging ideas in ways that might be new and beyond culture or gender norms can be supported by actively building reflexive capacity, and openly noting diverse ways of thinking as a starting point for new, more integrated interpretations (Gottschick, 2013). Existing structures of how research is designed and funded, how research teams work to complete objectives and what is considered successful outputs and outcomes need to be reshaped in integrated research.

Bartlett (2018) outlines eight criteria for success in international programmes of work. We outline these in Table 5 and show how, from our experience, integrated research can be explicitly considered. Fundamentally, it should be an explicit decision as to whether integrated research is the right approach for a given problem. 
Lessons learnt. Because community engagement can be done in so many ways, for different purposes, it requires a significant amount of planning and expertise to achieve the positive change typically intended for integrated research. We found our lessons learned related to four areas: (1) Requirements for effective community engagement; (2) Project design; (3) Individual and collective skills and competencies; and (4) Processes to support knowledge integration. We discuss these below with links to where our insights extend current literature on approaches to integrated research.

Requirements for effective community engagement. It is paramount that the community is engaged sensitively and that cultural procedures are followed as appropriate (such as approvals and who is approached first). This requires background research and/or experience to know the processes and who to approach. To make sure that time is spent appropriately it is important to know what other engagements have happened in the village and to allow sufficient time to build trust, achieve the project aims and foster agency over actions taken (and benefit the community). It is difficult to create sufficient trust and agency in a short, one-off visit, so ongoing engagement is likely to be required to support the community to maintain change. In our experience, if these conditions are met, it is less important which 'method' is used to gather data or build community capacity, although RAPTA is potentially more effective at enabling more critical systems thinking, envisioning the future and pathways to change than PRA and CLAP (but we were unable to sufficiently demonstrate this perception because of limited implementation of RAPTA in the community).

Project design. In terms of integrated research, we found that the project design and process of engagement had a greater impact on achieving the purpose of integrating knowledges in a meaningful way than the individual community engagement method. This design and communication were the most essential factors and they must be supported across scales from the individual to the organisation, through developing skills and competencies and a range of supporting structures and processes (see below).

Individual and collective skills and competencies. At the individual level, there must be a willingness to participate, share and explain ideas, to be open-minded and sensitive to language uses and limitations and to take responsibility to regularly check in on (mis)understandings (Campbell, 2005). There must also be a willingness to engage in complex intellectual work (negotiating epistemologies, building reflexivity) and additional roles and skills, such as communication, active listening, and flexibility to think outside of specific disciplines and experiences (Preston et al., 2015). At the team level, there must be processes in place to support open and inclusive communication (such as regular meetings which are well-attended and the ability to contribute via access to the internet and technology, for example).

Different individuals have different capacities and interests in integrated research (as do different teams, leaders and organisations). Being able to match capabilities and interests with the work required is an advantage, and where there are gaps, options to support may be required (e.g, adapting the design, adapting objectives or outputs, building capacity). Different individuals also have different world-views and expectations about the project and their own careers, which may be implicit or unrealised (Campbell, 2005). These assumptions take time to negotiate and in some cases a consensus is not possible or desirable, although clarifying expectations, roles and purposes is essential, especially if unequal power relationships have the potential to be disruptive to the overall project goal (Pooley et al., 2014).

The interviews highlighted that raising awareness of different epistemologies (Wickson et al., 2006; Rawluk et al., 2020) and world-views is a journey of building relationships and reflexive capacity, which is a new approach, new language and new skill for some of the team members. Building the reflexive capacity of individuals and teams engaged in integrated research is important (Gottschick, 2013) and requires explicit time and process to facilitate. Time spent face to face was an important factor for the Gambut Kita team to build reflexivity, through increasing understanding and empathy for other perspectives and developing a shared, project view. As the team included members across disciplines and both academic and non-academic partners, this also involved a period of accepting the validity of each other's different knowledge and experience and establishing acceptance of shared power and responsibility (Mobjork, 2010). Our experience also identifies that the on-ground partners are essential to managing the ongoing implementation of behaviour change and working across the boundary of knowledge production and knowledge use (Lemos, 2015).

Processes to support knowledge integration. There must also be explicit processes to support the integration of knowledge. This integration has also been called "boundary work" (Cash et al., 2003) and needs to happen within the team, as well as with other groups (the community). For this to occur, leaders need to recognise and reward (incentivise) the effort of good communication and set the standard for clear and inclusive communication. Leaders also need to set up explicit processes, tasks and responsibilities to support integration. In addition, leaders need to create opportunities for interaction and relationship building that form the foundation for good understanding. Organisations need to support funding and design arrangements that enable communication-for example, a dedicated 'neutral' project manager, or communication specialists, as well as adequate time, opportunity, and support for effective communication (including opportunities to meet face to face for new teams or geographically dispersed teams, language support and cultural and ethics training). This is in stark contrast to current trends towards reduced funding despite increasingly complex and integrated problems (Simon and Schiemer, 2015). Leadership training, training for early career researchers to work across disciplines and training to build skills in reflexivity and research evaluation are clear areas for research and development organisations to address (Lyall et al., 2015).

These findings echo Cornell et al. (2013), especially relating to the need for different organisational and personal orientations (e.g. longer time frames, different metrics of success, focus on reflexivity and willingness to learn), but we also identify the importance of time spent face to face, and building relationships and understanding, which requires specific management (and leadership) approaches. Even when all the stars align for successful integrated research in terms of the project individuals, team, leader and organisations, there will always be factors outside of the research team to control, including the politics of decision-making, corruption, inequity and power (Butler et al., 2014), or in our case, COVID-19 which has put a stop to international travel. Research that actively reflects on and draws out these broader implications and learning, especially where things are institutionally, culturally and technically 'messy', is desperately needed (Jefferson et al., 2020). This paper is our attempt to contribute to others navigating their own complexities in integrated research or community engagement by marking out the key areas of focus we found best supported our progress and highlighting the essential role of reflexivity to build capacity in 
ourselves as researchers and practitioners. In terms of the project itself, we responded to these findings by replanning and rescoping project activities to more explicitly integrate across different study objectives and opened communication between teams to share results more frequently. We also developed a theory of change for the project objectives and pathways and are developing more shared outputs.

\section{Conclusion}

Integrated research which effectively engages with relevant communities is increasingly recognised as an essential way to tackle complex socio-ecological challenges. Examining the ways in which livelihoods can be maintained on rewetted peatlands in Indonesia is certainly a complex problem in this category. We explored three different community engagement methods and reflected on these as a project team, along with the process of integrated research. We found that CLAP, PRA and RAPTA all have some similarities in their intentions and approach but also have some unique considerations. We hope that by accounting for these here, others will more readily be able to choose a suitable method and to be cognisant of what is involved. We conclude that different approaches are best matched to different problem contexts. When levels of uncertainty are high, change is rapid and complex, the problems are systemic in nature, and scales involved are beyond the community, our analysis suggests that RAPTA is a suitable approach to facilitating change because it explicitly deals with uncertain futures, theory of change, and maps out change options and pathways. PRA and CLAP are essentially the same approaches to achieving community empowerment, but CLAP may be better suited when longer-term relationships are required for ongoing programmes of work and PRA can achieve more targeted or initial engagements. In some contexts, combinations of methods may also be useful to consider, for example, theory of change from RAPTA may be readily added to CLAP and or PRA. All three methods have the ability to support integrated research but this may need to be a specific design consideration for PRA and CLAP.

Our reflections on integrated research show that it takes work at multiple scales to be effective, it is not only about individuals, nor any one method of community engagement. The barriers and opportunities we identify are relevant for organisations and leaders as well as teams and individuals to improve their chance of success in integrated research. We highlight the role of communication, trust, strong leadership, project design and explicit process and attention, including resourcing and evaluation metrics, in successfully achieving integrated research. We also highlight that time spent working face to face is key to overcoming disciplinary and geographic divides and achieving desired outcomes.

\section{Data availability}

The datasets generated during and/or analysed during the current study are not publicly available due to ethics limitations including consent for how the data will be used.

Received: 20 October 2020; Accepted: 29 July 2021;

Published online: 13 August 2021

\section{References}

Alexander K, Hobday A, Cvitanovic C, Ogier E, Nash K, Cottrell R, Fleming A, Fudge M, Fulton E, Frusher S, Kelly R, MacLeod C, Pecl G, van Putten I, Vince J, Watson R (2019) Progress in integrating natural and social science in marine ecosystem-based management research. Mar Freshw Res 70:71-83
Bammer G (2013) Disciplining interdisciplinary: integration and implementation sciences for researching complex real-world problems. Australian National University E Press, Australia

Bartlett AG (2018) Factors affecting the relative success of collaborative forestry research projects in Indonesia. Eur J Dev Res 30(5):892-913

Butler JRA, Suadnya W, Puspadi K, Sutaryono Y, Wise RM, Skewes TD, Kirono D, Bohe EL, Handayani T, Habibi P, Kisman M, Suharto-Hanartani I, Supartarningsih S, Ripaldi A, Fachry Y, Yanuartati Y, Abbas G, Ash A (2014) Framing the application of adaptation pathways for rural livelihoods and global change in eastern Indonesian islands. Glob Environ Change 28:368-382

Campbell LM (2005) Overcoming obstacles to interdisciplinary research. Conserv Biol 19:574-577

Cash DW, Clark WC, Alcock F, Dickson NM, Eckley N, Guston DH, Jager J, Mitchell RB (2003) Knowledge systems for sustainable development. Proc Natl Acad Sci USA 100:8086-8091

Castelloe P, Gamble D (2005) Participatory methods in community practice: popular education and participatory rural appraisal. In: Weil M, Reisch M (eds.) Handbook of community practice. Sage Publications, Thousand Oaks, pp. $261-275$

Chambers R (1994) The origins and practice of participatory rural appraisal. World Dev 22(7):953-969

Collard RC, Harris LM, Heynen N, Mehta L (2018) The antinomies of nature and space. Environ Plan E 1(1-2):3-24

Cornell S, Berkhout F, Tuinstra W, Tabara JD, Jager J, Chabay I, de Wit B, Langlais R, Mills D, Moll P (2013) Opening up knowledge systems for better responses to global environmental change. Environ Sci Pol 28:60-70

Cundill G, Currie-Alder B, Leone M (2019) The future is collaborative. Nat Clim Change 9:343-345

Dick M, Rous AM, Nguyen VM, Cooke SJ (2016) Necessary but challenging: multiple disciplinary approaches to solving conservation problems. FACETS $1: 62-82$

Dohong A, Aziz AA, Dargusch P (2018) A review of techniques for effective tropical peatland restoration. Wetlands 38:275-292. https://doi.org/10.1007/ s13157-018-1017-6

Dohong A, Aziz AA, Dargusch P (2017) A review of the drivers of tropical peatland degradation in South-East Asia. Land Use Policy 69:349-360. https://doi.org/ 10.1016/j.landusepol.2017.09.035

Fleming A, O'Grady AP, Mendham D, England J, Mitchell P, Moroni M, Lyons A (2019) Understanding the values behind farmer perceptions of trees on farms to increase adoption of agroforestry in Australia. Agron Sustain Dev 39(9). https://doi.org/10.1007/s13593-019-0555-5

Giesen W (2018) Tropical Peatland Restoration Report: the Indonesian case. Technical Report. Prepared by Mott MacDonald Consulting, Jakarta

Goldstein JE, Graham L, Ansori S, Vetrita Y, Thomas A, Applegate G, Vayda AP, Saharjo BH, Cochrane MA (2020) Beyond slash-and-burn: the roles of human activities, altered hydrology and fuels in peat fires in Central Kalimantan, Indonesia. Singap J Trop Geogr https://doi.org/10.1111/sjtg.12319

Gottschick M (2013) Reflexive capacity in local networks for sustainable development: integrating conflict and understanding into a multi-level perspective transition framework. J Environ Policy Plan 20(6):1-22

Hernandez KJ, Rubis JM, Theriault N, Todd Z, Mitchell A, Country B, Burarrwanga L, Ganambarr R, Ganambarr-Stubbs M, Ganambarr B, Maymuru D, Suchet-Pearson S, Lloyd K, Wright S (2020) The creatures collective: manifestings. Environ Plan E https://doi.org/10.1177/2514848620938316

Hu Y, Fernandez-Anez N, Smith T, Rein G (2018) Review of emissions from smoldering peat fires and their contribution to regional haze episodes. Int $\mathrm{J}$ Wildland Fire 27(5):293-312

International Union for Conservation of Nature 2019, viewed 14.11.19, https:// www.iucn.org/resources/issues-briefs/peatlands-and-climate-change

Jefferson U, Carmenta R, Daeli W, Phelps J (2020) Characterising policy responses to complex socio-ecological problems: 60 fire management interventions in Indonesian peatlands. Glob Environ Change 60:102027. https://doi.org/ 10.1016/j.gloenvcha.2019.102027

Kelly R, Mackay M, Nash KL, Cvitanovic C, Allison EH, Armitage D, Bonn A, Cooke SJ, Frusher S, Fulton EA, Halpern BS, Lopes PFM, Milner-Gulland EJ, Peck MA, Pect GT, Stephenson RL, Werner F (2019) Ten tips for developing interdisciplinary socio-ecological researchers. Socio-Ecol Pract Res 1:149-161

Lemos MC (2015) Usable climate knowledge for adaptive and comanaged water governance. Curr Opin Environ Sustain 12:48-52

Lyall C, Meagher L, Bruce A (2015) A rose by any other name? Transdisciplinarity in the context of UK research policy. Futures 65:150-162

Lyall C, Meagher LR (2012) A masterclass in interdisciplinarity: research into practice in training the next generation of interdisciplinary researchers. Futures 44:608-617

Marlier ME, DeFries RS, Kim PS, Koplitz SN, Jacob DJ, Mickley LJ, Myers SS (2015) Fire emissions and regional air quality impacts from fires in oil palm, timber, and logging concessions in Indonesia. Environ Res Lett 10(8):085005 
Medrilzam M, Smith C, Aziz AA, Herbohn J, Dargusch P (2017) Smallholder farmers and the dynamics of degradation of peatland ecosystems in Central Kalimantan, Indonesia. Ecol Econ 136:101-113

Miettinen J, Shi C, Liew SC (2016) Land cover distribution in the peatlands of Peninsular Malaysia, Sumatra and Borneo in 2015 with changes since 1990. Glob Ecol Conserv 6:67-78

Miettinen J, Hooijer A, Vernimmen R, Liew SC, Page SE (2017) From carbon sink to carbon source: extensive peat oxidation in insular Southeast Asia since 1990. Environ Res Lett 12(2):024014

Mobjork M (2010) Consulting versus participatory transdisciplinarity: a refined classification of transdisciplinary research. Futures 42:866-873

Muhamad N, Rieley JO (2001) Management of tropical peatlands in Indonesia: mega-reclamation project in Central Kalimantan. In: Rieley JO, Page S, Setiadi B (eds) Peatlands for people, natural resources, functions and sustainable management. Proceedings of the international symposium on tropical peatland, 22-23 August 2001, Jakarta, Indonesia. BPPT and Indonesian Peat Association, Jakarta, pp. 155-162.

Narayanasamy (2009) Participatory rural appraisal: principles, methods and application. Sage Publications, Los Angles

O'Connell D, Maru Y, Grigg N, Walker B, Abel N, Wise R, Cowie A, Butler J, Stone-Jovicich S, Stafford-Smith M, Ruhweza A, Belay M, Duron G, Pearson L, Meharg S (2019) Resilience, adaptation pathways and transformation approach. A guide for designing, implementing and assessing interventions for sustainable futures (version 2). CSIRO, Australia

Pooley SP, Mendelsohn JA, Milner-Gulland EJ (2014) Hunting down the chimera of multiple disciplinarity in conservation science. Conserv Biol 28(1):22-32

Preston BL, Rickards L, Fünfgeld H, Keenan RJ (2015) Toward reflexive climate adaptation research. Curr Opin Environ Sustain 14:127-135

Purnomo H, Shantiko B, Sitorus S, Gunawan H, Achdiawan R, Kartodihardjo H, Dewayani A (2017) Fire economy and actor network of forest and land fires in Indonesia. Forest Policy Econ. https://doi.org/10.1016/j.forpol.2017.01.001

Rawluk A, Beilin R, Bender H, Ford R (2020) Practices in socio-ecological research: interdisciplinary collaboration in 'adaptive doing'. Palgrave Macmillan, Switzerland

Roux DJ, Nel JL, Cundill G, O'Farrell P, Fabricius C (2017) Transdisciplinary research for systemic change: who to learn with, what to learn about and how to learn. Sustain Sci 12:711-726

Sanders AJP, Ford RM, Keenan RJ, Larson AM (2020) Learning through practice? Learning from the REDD+ demonstration project, Kalimantan Forests and Climate Partnership (KFCP) in Indonesia. Land Use Policy 91:104285

Sanders AJP, Ford RM, Mulyani L, Prasti HRD, Larson AM, Jagau Y, Keenan RJ (2019) Unrelenting games: multiple negotiations and landscape transformations in the tropical peatlands of Central Kalimantan, Indonesia. World Dev 117:196-210

Sanders AJP, da Silva Hyldmo H, Prasti HRD, Ford RM, Larson AM, Keenan RJ (2017) Guinea pig or pioneer: translating global environmental objectives through to local actions in Central Kalimantan, Indonesia's REDD+ pilot province. Glob Environ Change 42:68-81

Shah P (1994) Participatory rural appraisal, village planning, community managed extension and training for farm level forestry project in Vietnam. Consultation report for Vietnam-Sweden Forestry Cooperation Programme. Agriculture Publishing House, Hanoi.

Simon D, Schiemer F (2015) Crossing boundaries: complex systems, transdisciplinarity and applied impact agendas. Curr Opin Environ Sustain 12:6-11
Tress B, Tress G, Fry G (2006) Defining concepts and processes of knowledge production in integrative research. Springer, Dordrecht, The Netherlands.

Tress G, Tress B, Fry G (2004) Clarifying integrative research concepts in landscape ecology. Landsc Ecol 20:479-493

Uda SR, Hein L, Adventa A (2019) Towards better use of Indonesian peatlands with paludiculture and low-drainage food crops. Wetl Ecol Manag https:// doi.org/10.1007/s11273-020-09728-x

UNFCCC (2016) First nationally determined contribution republic of Indonesia. United Nations framework convention on climate change. http:// www4.unfccc.int, https://www4.unfccc.int/sites/ndcstaging/PublishedDocum ents/Indonesia\%20First/First\%20NDC\%20Indonesia_submitted\%20to\% 20UNFCCC\%20Set_November\%20\%202016.pdf. Accessed 31 Aug 2020

Wickson F, Carew AL, Russell A (2006) Transdisciplinary research: characteristics, quandaries and quality. Futures 38:1046-1059

\section{Acknowledgements}

Project grant number: FST/2016/144 Improving community fire management and peatland restoration in Indonesia. Many thanks to the interview participants for their time and insights. Figure 1 was prepared by Visual Knowledge. This work was funded by the Australian Centre for International Agricultural Research and the Australian Department of Foreign Affairs and Trade.

\section{Competing interests}

The authors declare no competing interests.

\section{Additional information}

Supplementary information The online version contains supplementary material available at https://doi.org/10.1057/s41599-021-00878-8.

Correspondence and requests for materials should be addressed to A.F.

Reprints and permission information is available at http://www.nature.com/reprints

Publisher's note Springer Nature remains neutral with regard to jurisdictional claims in published maps and institutional affiliations.

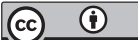

Open Access This article is licensed under a Creative Commons Attribution 4.0 International License, which permits use, sharing, adaptation, distribution and reproduction in any medium or format, as long as you give appropriate credit to the original author(s) and the source, provide a link to the Creative Commons license, and indicate if changes were made. The images or other third party material in this article are included in the article's Creative Commons license, unless indicated otherwise in a credit line to the material. If material is not included in the article's Creative Commons license and your intended use is not permitted by statutory regulation or exceeds the permitted use, you will need to obtain permission directly from the copyright holder. To view a copy of this license, visit http://creativecommons.org/ licenses/by/4.0/.

(c) Crown 2021 